\title{
SUCCESSFUL PREGNANCY OUTCOME FOLLOWING THE USE OF ESIKE'S TECHNIQUE TO TREAT UNCONTROLLABLE LIFE-THREATHENING POSTPARTUM HAEMORRHAGE: A CASE REPORT
}

\author{
Chidi Esike ${ }^{1}$ \\ ${ }^{1}$ Alex Ekwueme Federal University Teaching Hospital Abakaliki
}

October 19, 2020

\section{INTRODUCTION}

Postpartum haemorrhage(PPH) is the leading cause of maternal mortality worldwide ${ }^{1}$ with about $35 \%$ of all maternal deaths globally attributed to it $^{2}$ and the adverse effects more severe in the developing countries ${ }^{3}$. An African woman's lifetime risk of dying from pregnancy-related causes is about 100 times higher than that of a woman in a developed country ${ }^{3}$. Every year, about 14 million women around the world suffer from postpartum haemorrhage ${ }^{4}$ with uterine atony being the leading cause of postpartum haemorrhage whatever the mode of delivery. Its severe forms are often unexpected and may occur in the absence of recognized risk factor ${ }^{5}$. Postpartum heaemorrhage occurs in $4-6 \%$ of deliveries ${ }^{6}$ and it is severe in 1 to 2 percent of life births ${ }^{7}$.

There are many management modalities for postpartum haemorrhage ranging from the conservative use of drugs like oxytocin, misoprostol etc to prevent it to more conservative uterine sparing surgeries and finally hysterectomy as the final treatment ${ }^{8,9}$. Uterine compression sutures have been shown to be effective in the management of postpartum haemorrhage ${ }^{10,11}$ with reported success rates ranging from $76 \%$ to $100 \%$ with an added advantage of preservation of the uterus ${ }^{12,13}$. This makes them proven as essential treatment options for postpartum haemorrhage.

Apart from the B- Lynch sutures first reported in $1997^{17}$, various methods of uterine compression sutures have been proposed and have yielded good outcomes with success rates of $76-100 \%{ }^{12}$. In August 2020, the Esike's technique of uterine compression method was published as a new, safe, simple and effective treatment for massive life-threatening postpartum haemorrhage ${ }^{5}$. Its use preserves the uterus and the success rate is 89 percent $^{15}$.

Despite the impressive effectiveness and safety of uterine compression suture methods, concern has been raised in some quarters concerning its safety and preservation of fertility. A few studies have reported that use of uterine compression sutures can lead to changes in fertility that might have effect on subsequent pregnancies ${ }^{16-18}$. This has made it imperative for any pregnancy outcome from such methods especially new ones like the Esike's technique to be reported to the scientific community since subsequent pregnancies in women desiring more pregnancies is about the surest way of confirming, not just the safety and effectiveness of such methods, but also the usefulness of the preservation of the uterus that is amongst many other advantages that are inherent in the uterine compression methods of combating postpartum haemorrhage. We report a successful pregnancy outcome in a multipara with one previous caesarean section then who had placenta praevia type 4 and subsequently delivered by repeat caesarean section in her last pregnancy on 14 June 2017 and subsequently had life-threatening PPH that was controlled with the Esike's technique 
with preservation of her uterus. She conceived and successfully delivered a life $3.7 \mathrm{~kg}$ male baby with good outcome at term.

\section{THE CASE}

Mrs O.I, was referred to our center, Alex Ekwueme Federal University Teaching Hospital Abakaliki on $2^{\text {nd }}$ June 2017 at a gestational age of 32 weeks and 5 days with bleeding in pregnancy and was admitted into our antenatal ward through the Accident and Emergency unit of the hospital on account of recurrent painless unprovoked bright red vaginal bleeding of 9 hours duration. The bleeding was profuse with clots. She had changed two well-soaked pads. There was no dizziness or fainting attacks. She was referred from a private hospital where she booked. She had had 2 previous episodes of unprovoked vaginal bleeding at a gestational age of 25 weeks and 2 days and 5 days prior to presentation. On both occasions she was managed at the peripheral hospital where she booked. She came with an ultrasound scan result that showed type 4 placenta praevia.

In 2015 she had a term delivery of a $4.3 \mathrm{~kg}$ male neonate with Apgar scores of 6 in one and 10 in 5 minutes through an emergency caesarean section at a peripheral mission hospital on account of cephalo-pelvic disproportion

Examination revealed an anxious young lady in no obvious distress who was afebrile to touch, mildly pale but not jaundiced. The pulse rate was 98 beats per minute, moderate volume and regular and blood pressure was $110 / 70 \mathrm{mmHg}$ and she had no pedal oedema. The chest was clinically clear and the abdomen was uniformly enlarged with a symphisio-fundal height of $33 \mathrm{~cm}$. the uterus haboured a singleton fetus in longitudinal lie with cephalic presentation and a high floating presenting part. The fetal heart rate was 150 beats per minute and regular.

Inspection of the vagina showed a perineal pad that was mildly soaked with bright red blood but no active vaginal bleeding was seen per vagina. There was no digital examination. A diagnosis of antepartum haemorrhage secondary to placenta praevia at $32 \mathrm{wks} 5$ days gestation in a primipara was made.

Blood was collected for haemoglobin, grouping and crossmatching of 4 units of blood and other investigations, an abdominal ultrasound was asked for and an intravenous line was set up with one liter of ringers lactate solution started fast. She was admitted into the antennal ward for conservative management of her placenta praevia. Intra-muscular dexamethazone $12 \mathrm{mg}, 12$ hourly for 2 doses was prescribed for her among other medications.

The packed cell volume was $25 \%$ and the obstetric ultrasound on $2 / 6 / 17$ showed a single viable intra-uterine fetus in transverse lie with the head to the maternal left. There was good gross fetal body movement with a fetal heart rate of 130 beats per minute. Estimated gestational age was 33 weeks and 3 days and estimated fetal weight $2.7 \mathrm{~kg}$. There was no fetal anomaly noted. The placenta was sitting on the internal os completely covering it with mild bleed noted in the cervical os. There was no obvious retroplacental bleed seen. The liquor volume was adequate and the internal os was closed. There was no coexisting uterine mass. An impression of a viable 33 wks 3 days old gestation with placenta praevia type 4 was made.

She was transfused with 2 units of blood, placed on haematinics and other drugs and managed conservatively for 12 days till 14/6/17 when she started bleeding profusely again and was taken to the theatre for emergency lower segment caesarean section.

The operation went well as a live $2.5 \mathrm{~kg}$ male baby (length $40 \mathrm{~cm}$ and had circumference of $32 \mathrm{~cm}$ ) with Apgar scores of 9 in one minute and 10 in 5 minutes was delivered. Haemostasis was controlled as per departmental protocol with under running sutures used over the placental bed which stopped the bleeding. But the uterine refused to contract despite starting high dose oxytocin, repeating. ergometrine 0.5mg, giving sublingual misoprostol 800 microgramme etc. The bleeding persisted as the uterus was still atonic.. Two units of blood was transfused intra-operatively. A decision was made to carry out peripartum hysterectomy before the Esike's Technique was carried out and the bleeding stopped. The patient made uneventful recovery and 
was discharged home on the $6^{\text {th }}$ postoperative day. She had done well and on her $6^{\text {th }}$ week postnatal visit and was discharged from the clinic after being seen.

She presented to the hospital on $16^{\text {th }}$ February 2020 with inability to see her menstrual period for 3 months. Her last menstrual period was or $27 / 14 / 19$. Ultrasound confirmed an intrauterine pregnancy of 11 weeks and 3 days. She was booked for antenatal care, had an uneventful antenatal period and on $20^{\text {th }}$ of August 2020, she gave birth to a life $3.7 \mathrm{~kg}$ male baby with Apgar scores of 10 in one minute and 10 in 5 minutes through a repeat lower segment caesarean section. Estimated blood loss was $600 \mathrm{ml}$, Mother and baby were fine.

\section{DISCUSSION}

Postpartum haemorrhage is the leading cause of maternal mortality worldwide with uterine atony implicated in about 80 percent of its causes. Our patient had postpartum haemorrhage which was due to uterine atony. The compression suture method has been shown to be a safe and effective uterus-sparing method of treating this scourge of women. Effectiveness, safety and preservation of the uterus are about the greatest advantages of this method of treatment of postpartum haemorrhage especially for women who have not completed their reproductive carreer and had postpartum haemorrhage as in our patient. Esike's technique is a uterine compression method and it was effective and safe in controlling the life-threatening PPH in Mrs O.I. and it preserved her uterus. Pregnancy outcome can be taken to be one of the best confirmations of the safety and fertility preserving function of this method of combating postpartum haemorrhage. Mrs O.I. was treated with Esike's technique, subsequently got pregnant and successfully gave birth to her baby.

Despite the fact that the observation that many women who have experienced life-threatening delivery and received uterine compression suture treatment for their life threatening postpartum haemorrhage may less frequently wish for future pregnancy ${ }^{14}$ is understandable, for those that still desire pregnancy like Mrs O. I, getting pregnant is important, and indeed key, to their satisfaction, well being and fulfillment as women. The above-mentioned woman, Mrs O.I who had her life-threatening postpartum haemorrhage treated by Esike's technique got pregnant and had an uneventful antenatal period and a safe delivery of her baby without complications and with good Apgar score for her baby. These attest to the safety and good fertility preserving feature of the Esike's technique. The fact that the pregnancy preceding this good pregnancy outcome was further complicated by a previous caesarean section and placenta praevia type 4 and that the delivery of the preceding pregnancy was also by caesarean section further buttress both the effectiveness of the Esike's technique and its safety.

Other studies have also shown that other uterine compression methods of controlling postpartum haemorrhage are safe and have fertility sparing effects. Lui et al in their series of 23 women with uterine compression suture treatment for postpartum haemorrhage reported 3 women conceiving and 2 carrying their pregnancies to term successfully and deliverying ${ }^{16}$, concluding that uterine compression suture methods of treating $\mathrm{PPH}$ is safe and an effective alternative of avoiding hysterectomy with preservation of the uterus.

Also Kim et $\mathrm{al}^{19}$ found a subsequent pregnancy rate in 4 out of their 9 patients with uterine compression suture for postpartum haemorrhage who were followed up ie $44.4 \%$. An et al ${ }^{17}$ in their series recorded $34(81 \%)$ of women that desired pregnancy who got pregnant and delivered at term. This was not statistically different from those who did not have compression suture treatment and desired pregnancy, got pregnant and delivered at term.

From the foregoing, Esike's Technique has further been shown, like other uterine compression methods, to be effective, safe with not only preservation of the uterus but also to be fertility preserving. There is no doubt that definitely more of such pregnancy outcomes are still needed to further deepen these attributes of the Technique but this one case points salutarily in this direction.

\section{CONFLICT OF INTEREST AND FUNDING}

There was no conflict of financial, personal, political, intellectual and religious interest. 


\section{CONTRIBUTION TO AUTHORSHIP}

COUE was significantly involved in the conception, planning, carrying out the work and writing up of this paper.

\section{PATIENT'S CONSENT}

Patient and her husband's consent were obtained to publish this paper

\section{FUNDING STATEMENT}

There was no funding from anywhere for this work

\section{REFERENCES}

Say L, Chou D, Gemmill A, Tuncalp O, Moller AB et al. Global causes of maternal deaths: A WHO Systematic analysis. Lancet Glob Health 2014; 2 e323-e3

2. Countdown to 2015: maternal, newborn and child survival (internet) WHO and UNICEF 2012. Available at: https://www.countdown15mnch./or/documents/2012report/2012complet. Pdf Assessed $4^{\text {th }}$ October 2020 .

3. Trends in maternal mortality: 1990 to 2010 WHO, UNICEF, UNFPA and the World Bank estimates. Geneva WHO, 2012 available at http://whyglibocto.who.int/publications/2012/978924150363 Leng.pdf. last assessed 1 September 2020.

4. Miller S, Lester F, Heinsleigh P. Central Europe University Prevention and treatment of postpartum haemorrhage: New advances for low -resources settings. The Journal of Midwifery and women's health 2004,49(4): 283-92

5. Mathai M, Gulmezoglu AM, Hill S. Saving Women's Lives: Evidence based recommendations for the prevention of postpartum haemorrhage. Bull world Health Organ 2007, 85:3-323

6. American College of Obstetrics and Gynecology. ACOG Practice Bulletin: Clinical management guidelines for obstetricians - gynaecologists number 76 October 2006. Postpartum haemorrhage Obstet Gynecol 2006; 100: $1039-1047$

7. Matsuzaki S, Jitsumori M, Hara T et al. Systematic review on the needle and suture types of uterine compression sutures: a literature review. BMC Surg 2019; 19 (196) https://doi.org/10.1186/s/ 2893-0190660-Z

8. Mousa HA, Alfirevic Z. Treatment for primary postpartum haemorrhage. Cochrane database. Sys Rev .2007; 1: CD 003249

9. Cunningham FG, Leveno KJ, Bloom SL, Hauth JC, Rouse DJ, Spongy. Obstetric Hemorrhage. In: FG Cunningham, KJ Leveno, SL Bloom, SL Hauth, DJ Rouse, CY Spong,. (eds) Williams Obstetrics $23^{\text {rd }}$ edition. New York: McGraw Hills Medical, 2010: 757-803.

10. Muswi MSS, Buchmann EA, systematic review of maternal near-miss and mortality due to postpartum haemorrhage. Int J Gynecol Obstet 2017; 137: 1-7

11. Committee on practice B.O Practice Bulletin No 183, Postpartum haemorrhage Obstet Gynecol 2019, 130: e168-e86.

12. Matsubara S, Yano H, Ohkuchi A, Kuwata T, Usui R, Suzuki M, Uterine compression sutures for postpartum haemorrhage: an overview Acta Obstet Gynecol Scand 2013, 92: 378-85.

13. Suzuki Y, Matsuzaki S, Mimura K et al. Investigation of perioperative complications associated with the use of uterine compression sutures. Int J Gynecol Obstet 2017, 139 (I) https://dol.orgl10.1002/ijgo.12249 
14. B-Lynch C, Coker A, Lawal A, Abu J, Cowen MJ. The B-Lynch Surgical technique for the control of massive postpartum haemorrhage: An alternative to hysterectomy? Five cases reported. Br J Obstet, Gynaecol 1997, 104: 372-375.

15. Esike COU. A Uterus-preserving treatment for uncontrollable postpartum hemorrhage: Esike's technique. Obstet Gynecol 2020; 136(3): 466-469 doi:10.1097/AOG.0000000000003947

16. Liu S, Mathur M, Tagore S. Complications and pregnancy outcome following uterine suture for postpartum haemorrhage: a single center experience. J Obstet Gynaecol, 2014; 34:383-386

17. An GH, Ryu HM, Kim MY, Han JY, Chung TH, Kim MH -Outcome of subsequent pregnancies after uterine compression sutures for postpartum hemorrhage. Obstet gynecol 2013, 122 565-570

18. Duomouchtsis SK, Nicolopolous K, Talaulikar V, Krishna A, Arulkumaran S. Menstrual and fertility outcomes following the surgical management of postpartum haemorrhage: a systematic review BJOG 2014; 121: $282-388$

19. Kim ML, Hur Y, Rya H, Lee MJ, Seong ST Shin JS. Clinical outcome of prophylactic compression sutures for treatment of uterine atony during caesarean delivery of twins. BMC Pregnancy and childbirth 2020, 20:40.doi: 10.1186/s/ 12884-019-2716-6 